\title{
A prospective study of the factors affecting anticoagulant control in a hospital out-patient clinic
}

\author{
A. M. M. SHEPHERD*+ \\ B.Sc., M.R.C.P. \\ L. J. CHRISTOPHER $\dagger$ \\ M.D., M.R.C.P.I. \\ I. H. STEVENSON* \\ B.Sc., Ph.D. \\ C. R. HENNEY $\dagger$ \\ R.G.N., S.C.M. \\ Y. BROWN* \\ B.Sc. \\ *Department of Pharmacology and Therapeutics, and †Medicines Evaluation and Monitoring \\ Group, University of Dundee, Ninewells Hospital, Dundee DDI 9SY
}

\begin{abstract}
Summary
Anticoagulant control (as indicated by the percentage of Thrombotest values outside a defined range) was determined in out-patients attending a hospital anticoagulant clinic and the influence of patients' age and sex, indication for anticoagulation, concurrent drug therapy and duration of anticoagulant treatment studied. Of these factors, duration of treatment was most important, control being particularly poor in the first 6 months $(40 \%$ of Thrombotest values outside the $5-15 \%$ range, compared with $17 \%$ in patients treated with anticoagulants for more than 2 years). Control was also influenced by patients' age and the data supported previous evidence of an increased sensitivity to anticoagulants in the elderly.
\end{abstract}

\section{Introduction}

Oral anticoagulants belong to a relatively small group of drugs in which the effect of the drug is easily assessed. Nevertheless, a previous retrospective study (O'Malley et al., 1977) showed that, for in-patients treated with warfarin, under $30 \%$ of Thrombotest $\S$ values were within the accepted therapeutic range of anti-coagulant control $(5-15 \%)$.

A follow-up to these findings is now reported in which a prospective study was carried out with the objectives of determining firstly the degree of anti-

¥ Present address: Division of Clinical Pharmacology, University of Texas, Health Sciences Centre at San Antonio, San Antonio, Texas, U.S.A.

Correspondence: Dr I. H. Stevenson, Department of Pharmacology and Therapeutics, University of Dundee, Ninewells Hospital, Dundee DD1 9SY.

$\S$ Thrombotest Owren, B.D.H. Chemicals. coagulant control in out-patients and secondly the $\vec{\nabla}$ influence of the following factors on anticoagulant $\mathbb{D}$ control - patient's age and sex, indication for anti- $\frac{\mathscr{T}}{3}$ coagulation, duration of anticoagulant therapy an concomitant medication.

\section{Patients and methods}

One hundred and thirty-nine patients ( 85 wome and 54 men) attending the anticoagulant out-patient clinic in Ninewells Hospital, Dundee, were randomly selected from a total clinic population of approximately 250 . The ages of the patients studied ranged $\frac{}{\Phi}$ from 21 to 83 years, with 111 of the patients aged between 40 and 80 years. One hundred and nine patients were receiving warfarin and 30 phenindione.

All patients gave fully informed consent to their inclusion in the study. On entry to the study, information was obtained for each patient on age, $\frac{3}{3}$ weight, sex, indication for, and duration of anticoagulation (as recorded on the patient's anticoagula- 3 . tion card), anticoagulant drug and dose, coincidental disease and concomitant drug therapy (both prescription and 'over-the-counter').

At four consecutive clinic attendances, anticoagulant dose and control and any alterations in $\frac{\rightarrow}{0}$ concomitant drug therapy were recorded. Recording of Thrombotest results, regulation of warfarin $\tilde{N}$ dosage, and decision as to frequency of attendance $N$ were undertaken by the normal clinic staff. The N criterion of effective anticoagulation at the clinic ${ }_{\sigma}^{\omega}$ was a Thrombotest reading between 5 and $15 \%$ of normal. From the 4 Thrombotest readings? obtained for each patient, the percentage of observa- $\stackrel{\Phi}{\rightarrow}$ tions outside the $5-15 \%$ range was calculated. As ? previously (O'Malley et al., 1977), the periods when 
loading and tailing-off doses were being given were excluded and, in studying the influence of concomitant drug therapy on anticoagulant control, drugs were divided into 3 groups: Group I (known to interact), Group II (likely to interact) and Group III (no suspicion of interaction). Where drugs from more than one group were prescribed, the therapy was described as Group I whenever a Group I drug was involved and Group II when Group II and Group III drugs were given.

\section{Results}

For the total group of 139 patients studied, the duration of anticoagulant therapy had a marked influence on the proportion of Thrombotest results outside the $5-15 \%$ range (Fig. 1). Control improved steadily over the first 2 years, $67 \%$ of Thrombotest results being outside the control range for patients treated for 0-3 months, compared to $16 \%$ at 19-24 months. With patients given anticoagulants for more than 2 years, $20 \%$ of values on average were outside the $5-15 \%$ range. In the case of 30 of the 34 patients who had been treated for between 2 and 4 years, their anticoagulant records were examined retrospectively to determine the control during their first 2 years of therapy. The results for these patients when analysed in a similar way show the same trend, indicating that anticoagulant control progressively improved over the first 2 years (Fig. 2).

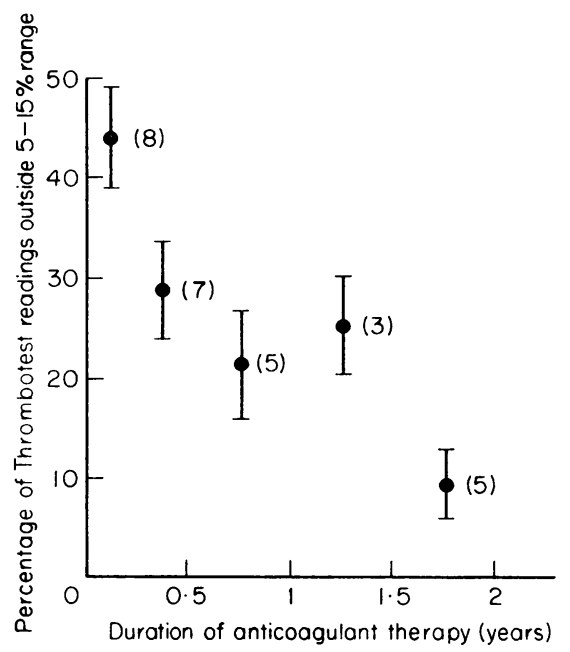

Fig. 2. Relationship between anticoagulant control and duration of anticoagulant therapy (retrospective study of records of thirty patients maintained on anticoagulants for 2-4 years). Results are shown as mean \pm s.e. mean, with the number of patients in parentheses. The results for the period 18 months-2 years are significantly lower than the other results shown.

Because of this marked alteration in quality of control over the first 2 years, only the data from 92 patients given anticoagulants for more than 2 years were analysed further. There was no

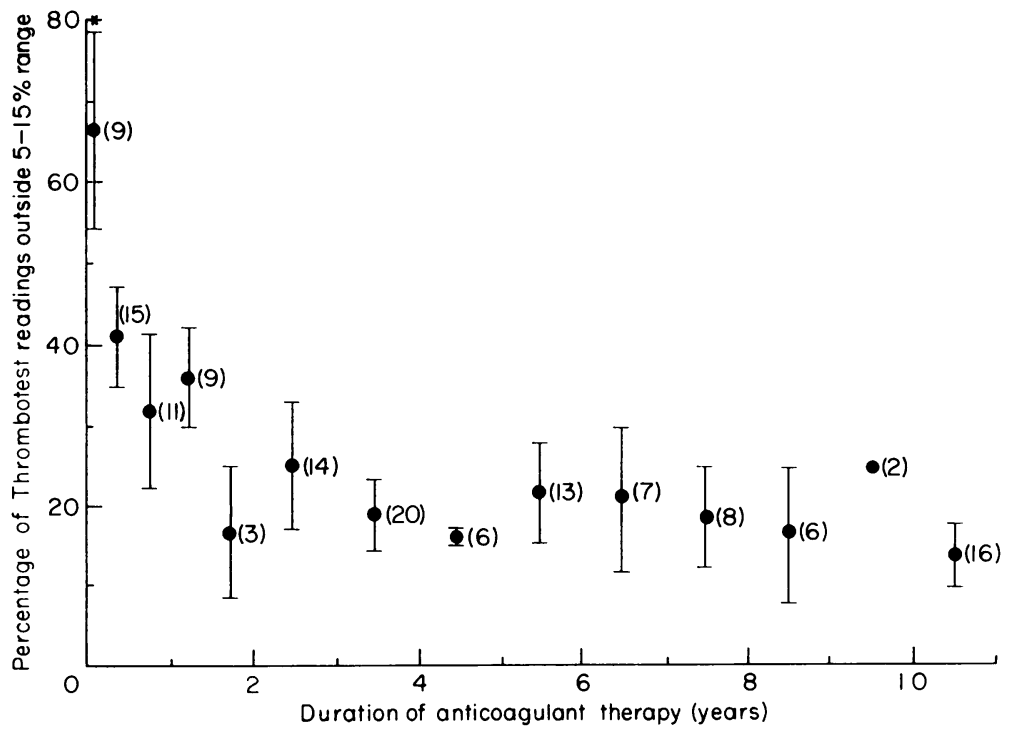

Fig. 1. Relationship between anticoagulant control and duration of anticoagulant therapy. Results for the total group of 139 patients studied are shown as mean \pm s.e. mean, with the number of patients for each period of treatment given in parentheses. The results for the first two periods of assessment, i.e. 0-3 months and 3-6 months are significantly higher than those for all periods after 18 months. 
significant sex difference in anticoagulant control (Table 1). With patients who were receiving only oral anticoagulant drug therapy, $9 \%$ of the Thrombotest values were outside the $5-15 \%$ range (Table 1). However, for patients who were given drugs known (Group I) or thought (Group II) to interact with anticoagulants, the proportion was higher, significantly so in the case of Group II drugs.

The indications for anticoagulants are given in Table 2, the commonest indication, as expected, being rheumatic heart disease, with deep venous thrombosis, myocardial infarction and cerebrovascular accident less common. The proportion of Thrombotest readings outside the defined range was similar in patients receiving anticoagulants for these conditions.

In assessing the effect of age on both anticoagulant control and warfarin requirement, only for patients aged between 40 and 70 years did the numbers allow statistical analysis to be carried out (Fig. 3). Both warfarin dose (on a weight-related basis) and Thrombotest value tended to be lower in the 60 69 years age group than in the younger groups, although individually these differences did not reach statistical significance. However, values of the product of these two interdependent variables, warfarin dose and Thrombotest percentage, when plotted against age, showed a significant agerelated difference (Fig. 3).

\section{Discussion}

Oral anticoagulants belong to a relatively small group of drugs in which the effect of the drug is easily assessed. The therapeutic aim is clearly defined in terms of objective measurement, e.g. Thrombotest level between 5 and $15 \%$ of normal and a good dose-effect relationship exists. Previous re-
TABLE 1. The effect of sex and concomitant drug therapy on 3 anticoagulant control

\begin{tabular}{lccc}
\hline Patient group & $\begin{array}{c}\text { No. of } \\
\text { patients }\end{array}$ & $\begin{array}{c}\text { Age } \\
\text { (years) }\end{array}$ & $\begin{array}{c}\text { Percentage of } \\
\text { Thrombotest } \\
\text { readings outside } \\
5-15 \% \text { range }\end{array}$ \\
\hline All patients & 92 & $54 \pm 1$ & $18 \pm 2$ \\
Male & 29 & $57 \pm 2$ & $16 \pm 4$ \\
$\quad$ Female & 63 & $54 \pm 2$ & $22 \pm 7$ \\
Concomitant drugs & 8 & $53 \pm 4$ & $9 \pm 5$ \\
$\quad$ None & 12 & $56 \pm 2$ & $25 \pm 8$ \\
Group I drugs & 17 & $50 \pm 2$ & $29 \pm 5^{*}$ \\
Group II drugs & 55 & $55 \pm 1$ & $15 \pm 3$ \\
Group III drugs & 55 & \\
\hline
\end{tabular}

These data relate to patients maintained on anticoagulants for more than 2 years and are expressed as mean \pm s.e. mean. 3

* Indicates significantly different from 'anticoagulant if only' group.

TABLE 2. Anticoagulant control and indication for anti- $\infty$ coagulation

\begin{tabular}{|c|c|c|c|}
\hline Indication & $\begin{array}{c}\text { No. of } \\
\text { patients }\end{array}$ & $\begin{array}{l}\text { Percentage of } \\
\text { Thrombotest } \\
\text { readings outsid } \\
5-15 \% \text { range }\end{array}$ & \\
\hline $\begin{array}{l}\text { Rheumatic heart disease } \\
\text { Deep venous thrombosis } \\
\text { Myocardial infarction } \\
\text { Cerebrovascular accident } \\
\text { Peripheral vascular disease } \\
\text { Other }\end{array}$ & $\begin{array}{r}63 \\
9 \\
6 \\
5 \\
4 \\
5\end{array}$ & $\begin{array}{r}21 \pm 3 \\
17 \pm 4 \\
13 \pm 9 \\
17 \pm 7 \\
6 \pm 6 \\
10 \pm 6\end{array}$ & 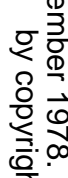 \\
\hline
\end{tabular}

These data relate to patients maintained on anticoagulants for more than 2 years and are expressed as mean \pm s.e. mean.

ports have however indicated that this ideal is difficult to attain in practice and that, even in $\varrho$ specialist centres, desired anticoagulation levels were $\overrightarrow{\overrightarrow{0}}$ attained on only about $50 \%$ of the occasions (Borch-

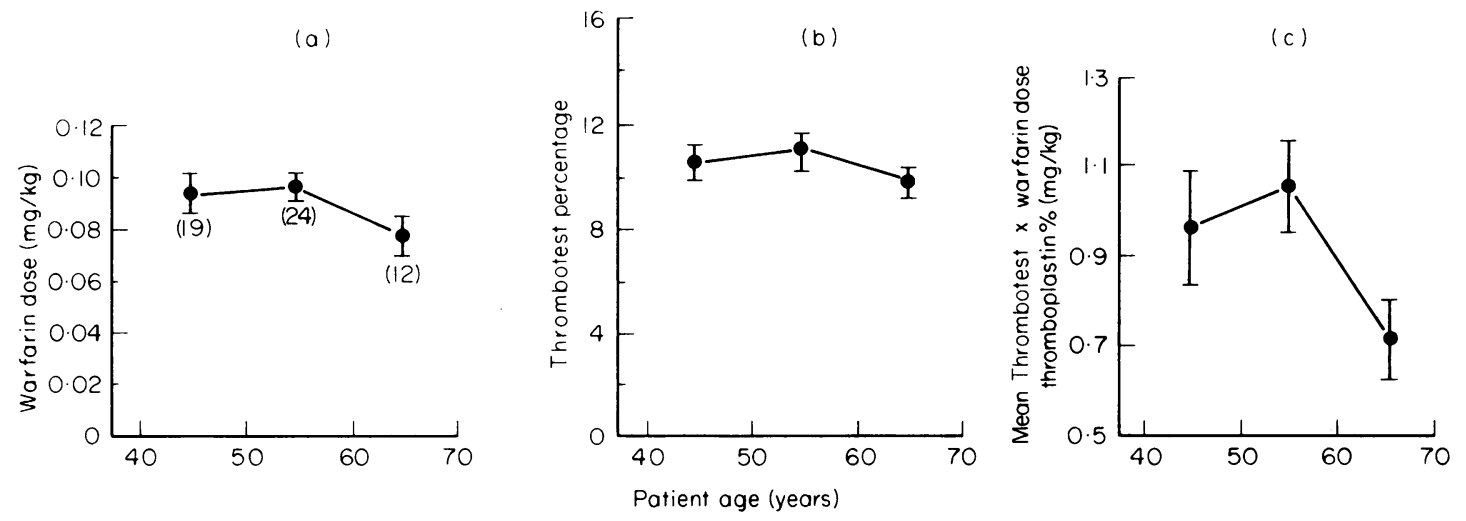

FIG. 3. Relationship between age of patient and warfarin dose/effect. (a) Warfarin dose. (b) Thrombot est response. (c) Thrombotest $\times$ warfarin dose. Results are shown as mean \pm s.e. mean, with the number of patients in parentheses. For the data on the product of warfarin dose $\times$ Thrombotest the results are significantly lower in the 60-69 years age group than in the 50-59 age group. 
grevink et al. 1968; Report of the Working Party on Anticoagulant Therapy in Coronary Thrombosis to the Medical Research Council, 1969; Report of an International Anticoagulant Review Group, 1970; O'Malley et al., 1977).

The present study on out-patients demonstrates that an appreciable proportion of Thrombotest values were outside the defined range, particularly in out-patients treated for less than 2 years, and underlines the need for careful out-patient follow-up (Table 3). While the basis of anticoagulant control assessment is not strictly comparable with that in a previous in-patient study (O'Malley et al., 1977), the indications are, however, that control is better than in patients in hospital (Table 3). In both studies, under-anticoagulation predominates.

The most striking factor related to lack of anticoagulant control was, surprisingly, the duration of treatment. In the first 6 months of anticoagulant therapy, $40 \%$ of Thrombotest values were outside the $5-15 \%$ range, decreasing to $16 \%$ in the 18- to 24-month period, and remaining relatively stable thereafter. A possible explanation for this apparent improvement in control was that the more poorly controlled patients were being lost to followup but a retrospective check of the anticoagulant records of patients taking anticoagulants for more than 2 years also revealed poorer control during their first 2 years of therapy.

Other factors affecting control were also examined, such as concomitant drugs, etc., but no significant differences between the $<2$ years versus $>2$ years groups were found. The most likely explanation would appear to be a lack of patient compliance in taking their medication as prescribed in the early stages of treatment and in favour of this is the general tendency toward under-anticoagulation, i.e. Thrombotest values $>15 \%$

TABle 3. Anticoagulant control in in-patients (retrospective study) and out-patients (prospective study)

\begin{tabular}{|c|c|c|c|}
\hline Thrombotest range & $\begin{array}{c}\text { In- } \\
\text { patients* } \\
(177) \\
\%\end{array}$ & $\begin{array}{c}\text { Whole } \\
\text { group } \\
(139) \\
\%\end{array}$ & $\begin{array}{l}\text { t-patients } \\
\text { Maintained on } \\
\text { anticoagulants } \\
\text { for more than } \\
2 \text { years (92) } \\
\%\end{array}$ \\
\hline $\begin{array}{l}\text { Within } 5-15 \% \text { whole } \\
\text { period } \\
\text { Less than } 5 \% \text { at }\end{array}$ & 28 & 35 & 48 \\
\hline $\begin{array}{c}\text { some time } \\
\text { More than } 5 \%\end{array}$ & $\begin{array}{l}25 \\
68\end{array}$ & $\begin{array}{l}12 \\
58\end{array}$ & $\begin{array}{l}10 \\
46\end{array}$ \\
\hline
\end{tabular}

* Data of O'Malley et al. (1977). The data for in-patients relate to all Thrombotest values obtained while those for the out-patients relate to the values obtained at four visits to the anticoagulant clinic. In both cases, loading and tailingoff data were excluded.
In patients treated for more than 2 years, one reason for variation in Thrombotest values could be the use of concomitant drugs which may interact with anticoagulants. A recent study (Williams, Griffin and Parkins, 1976) demonstrated that increased instability of anticoagulant control was related to the number of concomitant drugs taken. Surprisingly in the present study, the use of drugs known to interact with anticoagulants did not correlate more strongly with reduced control than the use of drugs with less evidence of such interaction. No obvious explanation for this was found although this may be in agreement with the opinion that there is a general lack of information on the clinical significance of many drug interaction effects (Crooks $e t$ al., 1977). However, in patients with no recorded history of taking Group I or Group II drugs, the initial poor control period still persisted.

While the degree of anticoagulant control did not seem to vary with age in patients in the range 40-70 years, examination of daily dosage of warfarin adjusted for weight revealed that patients between 60-69 years received a lower average daily dose than patients between 40 and 59 years old (Fig. 3). Thrombotest values also tended to be lower in the 60-69 years age group. While there were no age-related differences of statistical significance in either percentage of Thrombotest values outside the 5-15\% range, or in weight-related warfarin dose when taken individually, the product of these plotted against age demonstrated fairly clearly an agerelated difference. Although the influence of age is less striking than in the authors' previous study (O'Malley et al., 1977), the data support the suggestions of an increased sensitivity of the elderly to anticoagulants (O'Malley et al., 1977; Shepherd et al., 1977).

\section{Acknowledgments}

This work was supported by grants from the Medical Research Council, the Scottish Home and Health Department, and the Department of Health and Social Security. The authors wish to acknowledge the co-operation in this study of the nursing, and medical and technical staff of the Ninewells Anticoagulant Out-patient Clinic.

\section{References}

Borchgrevink, C.F., Bjerkelund, C., Abrahamsen, A.M., Bay, G., Borgen, P., Grande, B., Helle, I., Kuorstad, H., Petersen, A.M., Rorvik, T., Thorsen, R. \& OdeGAARD, A. (1968) Long term anticoagulant therapy after myocardial infarction in women. British Medical Journal, 3, 571.

Crooks, J., Stevenson, I.H., Shepherd, A.M.M. \& Moir, D.C. (1977) The clinical significance and importance of drug interactions. In: Drug Interactions (Ed. by GrahameSmith, D.G.), pp. 3-13. Macmillan Press, London.

O'Malley, K., Stevenson, I.H., Ward, C., WoOd, A.J.J. \& CrooKs, J. (1977) Determinants of anticoagulant control in patients receiving warfarin. British Journal of Clinical Pharmacology, 4, 309. 
Report of an International Anticoagulant Review Group (1970) Collaborative analysis of long-term anticoagulant administration after acute myocardial infarction. Lancet, i, 203.

REPORT OF THE WORKING PARTY ON ANTICOAgulant Therapy IN CoRonary Thrombosis to THE MEdical RESEARCH Council (1969) Assessment of short term anticoagulant administration after cardiac infarction. British Medical Journal, 1, 335.
ShePherd, A.M.M., Hewick, D.S., Moreland, T.A. \&

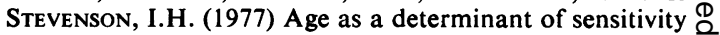
to warfarin. British Journal of Clinical Pharmacology, 4, 315.

Williams, J.R.B., Griffin, J.P. \& Parkins, A. (1976) Effect $\overrightarrow{\overline{\bar{D}}}$ of concomitantly administered drugs on the control of long term anticoagulant therapy. Quarterly Journal of Medicine, 45, 63. 